\title{
New Interpretation for Libyan Desert Glass Formation
}

\author{
Samir Ahmed Hamouda, Fatma Milad Elsharif \\ Department of Physics, University of Benghazi, P.O.Box 9480, Benghazi, Libya
}

Email address:

dr_s_hamouda@yahoo.ie (S. A. Hamouda), F.elsharif@gmail.com (F. M. Elsharif)

\section{To cite this article:}

Samir Ahmed Hamouda, Fatma Milad Elsharif. New Interpretation for Libyan Desert Glass Formation. International Journal of Astrophysics and Space Science. Vol. 1, No. 4, 2013, pp. 23-28. doi: 10.11648/j.ijass.20130104.13

\begin{abstract}
Ever since the discovery of Libyan Desert Glass in the southwest corner of the Great Sand Sea near the Libyan border, its source of formation has become the subject of controversy that still has not been resolve. This paper introduces a general description of Libyan Desert Glass. It presents briefly different theories explaining its formation. This paper introduces also new interpretation for Libyan Desert Glass formation. This interpretation suggests a meteorite impact mechanism. In this paper, the study of meteorite impact mechanism of BP and Oasis craters was carried out for the first time using a simple model. Calculations have shown that change in temperature for the target materials (sand) because of meteorite impact could explain the formation mechanism of Libyan Desert Glass that took place about 29 million years ago.
\end{abstract}

Keywords: Materials Characteristics, Meteorite, Meteorite Impact Mechanism, Shock Wave, Geochemical Principles, Technology of Earth Mapping, Astrophysics, Space Science, NASA

\section{Introduction}

Libyan Glass Desert (LDG) is a type vaguely of natural glass rich in silica amounts to approximately (96.5 - 99 Wt. \% SiO2) [1]. It is located (scattered) in an area of approximately $6500 \mathrm{~km}^{2}$ between the dunes in the southwest corner of the Great Sand Sea in the west of Egypt, near the Libyan border in Egypt sites. The location of (LDG) was one of the most remote and inhospitable regions on earth and a place for fabulous discovery [2-4]. The name Libyan Desert Glass is no true sense of the word in the description of the geographical boundaries, but refers to the traditional name of the desert [1].Figure1. Shows the location of (LDG).

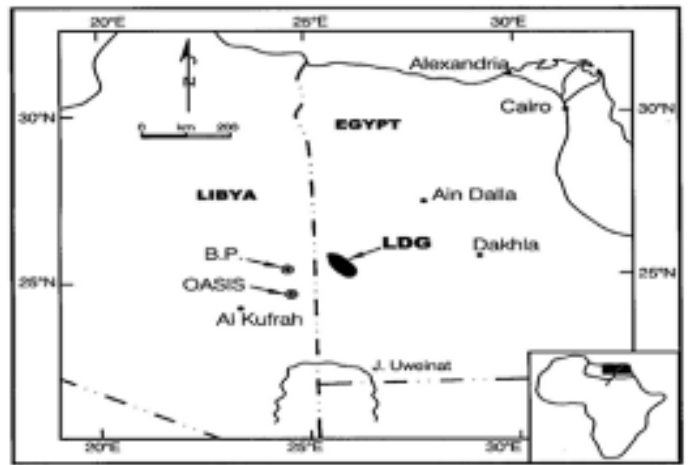

Figure1. Geographical location of (LDG)(taken from [1]).
The first detailed scientific report for (LDG) was attributed to Clayton and Spencer in 1932[5], when they conducted a survey in the area and discovered unknown glass models, yellow and green pale scattered on the surface of the sand dunes. Detailed papers of this topic can be found in [6-7]. Figure2. Shows the state of the (LDG) found. Examining the collected glass samples showed irregular shapes with signs of sand friction and other corrosion features. Its fission-track age has been determined at around 29 million years ago [8-10]. Figure3. Shows some fragments of (LDG).

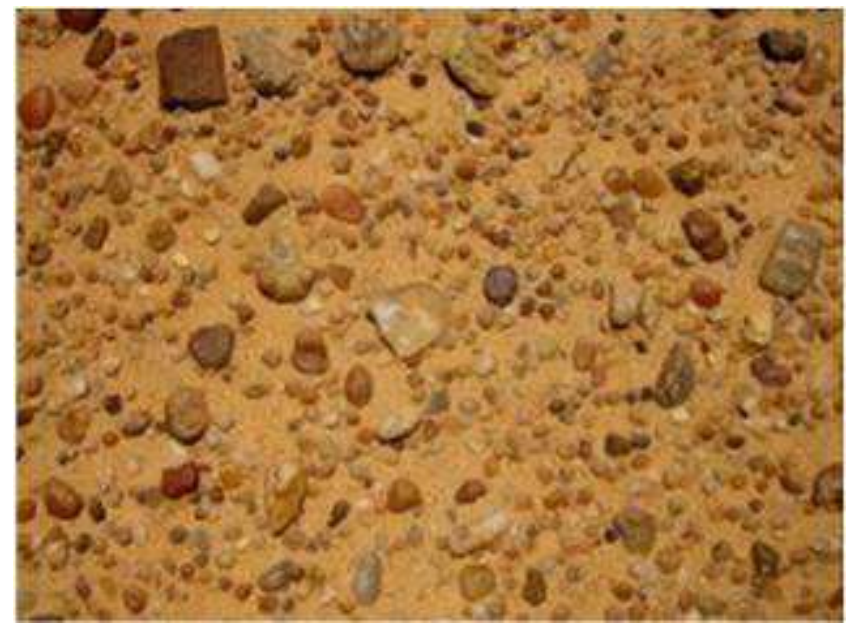

Figure2. Shows the scattered (LDG) found, (taken from [11]) 

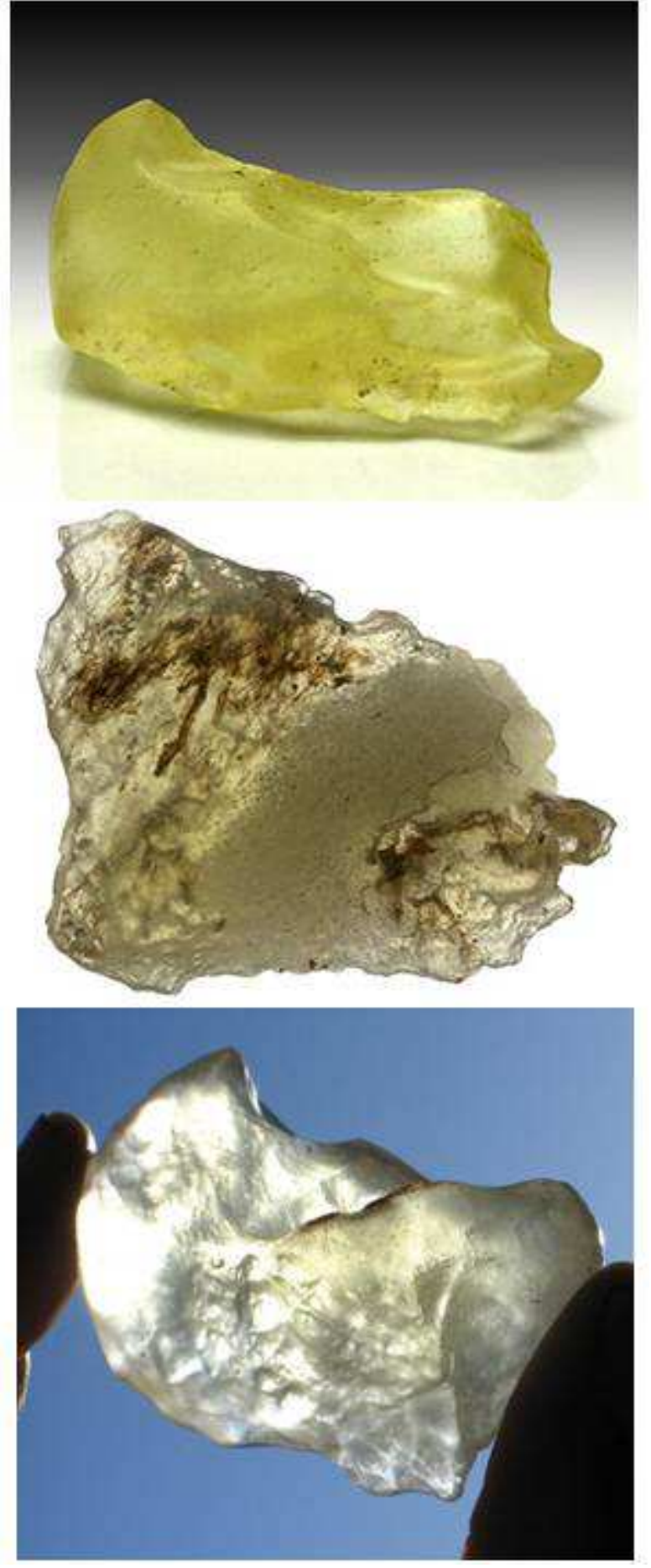

Figure3. Shows some types of (LDG), (Taken from [12]).

\section{Characteristics of the (LDG)}

Libyan Desert Glass exhibits a noteworthy number of unique characteristics [13]:

- Has a lower refractive index of 1.4616

- Has a lower specific gravity 2.21

- Has the highest proportion of silica $98 \%$

- Has the highest percentage of $0.064 \%$ water

- Has the highest viscosity
- Has irregular shapes

- Has different colors (see figure2 and figure3).

Since the discovery of the (LDG), it has fascinated scientists and researchers who were puzzled over its formation. Despite the fact that many studies concerning the formation of (LDG) have been carried out, the source of (LDG) has become the subject of controversy from some of the perspective researchers, that still has not been resolved [3].

\section{Theories and interpretations for (LDG) Formation}

At present time, there are many theories that gave many interpretations for the formation of Libyan Desert Glass, including [14]:

1 - Formed due to terrestrial volcanoes act.

2- Created by meteorites impact with Earth.

3 - Formed due to lunar volcanoes act

4- Formed by lightning activity that hit the ground

5- Formed by hot volcanic cloud explosion.

6- Formed by forest fires

However, researchers did not recognize the reason for the presence of (LDG) until 1967, using Space and aerial photography of the (LDG) area [15]. The images obtained showed two craters one is called BP crater. This crater has a diameter of $2 \mathrm{~km}$ and is located at $\left(25^{0} 19 \mathrm{~N}, 24^{0} 20 \mathrm{E}\right)$. The other crater is called Oasis crater. This crater has a diameter of $18 \mathrm{~km}$ and is located at $\left(24^{0} 35 \mathrm{~N}, 24^{0} 24 \mathrm{E}\right)$. The separation distance between the two craters is $80 \mathrm{Km}$. Figure 4 with the help of figure1 show the locations of BP and Oasis craters.

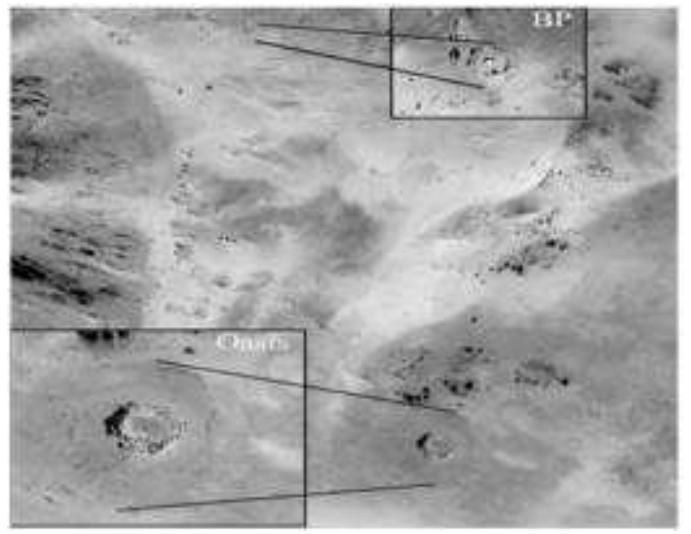

Figure 4. BP and Oasis crater as shown using Space and aerial Photography (Taken from [15]).

Each of these craters is located in the Kufra Basin near the Libyan-Egyptian border. The names BP and Oasis for the craters went back to the exploration teams contributed by the oil companies at that time. Figure4 shows the structure of a meteorite impacts with earth. These impacts suggest the possibility of a connection between the Libyan Desert Glass formation and meteorite impact mechanism with the ground. 


\subsection{The BP Crater}

The existence of the BP crater is likely to be due to a meteorite impact with ground. The overall shape of the crater shows high corrosion features. Figure 5 shows the structure of this crater. As is shown in the figure5, the crater is composed of two rings and a peak in the middle. The inner ring diameter is $2 \mathrm{~km}$ and an average height of $30 \mathrm{~m}$. The outer ring diameter is $2.8 \mathrm{~km}$ and a height of $15 \mathrm{~m}$.

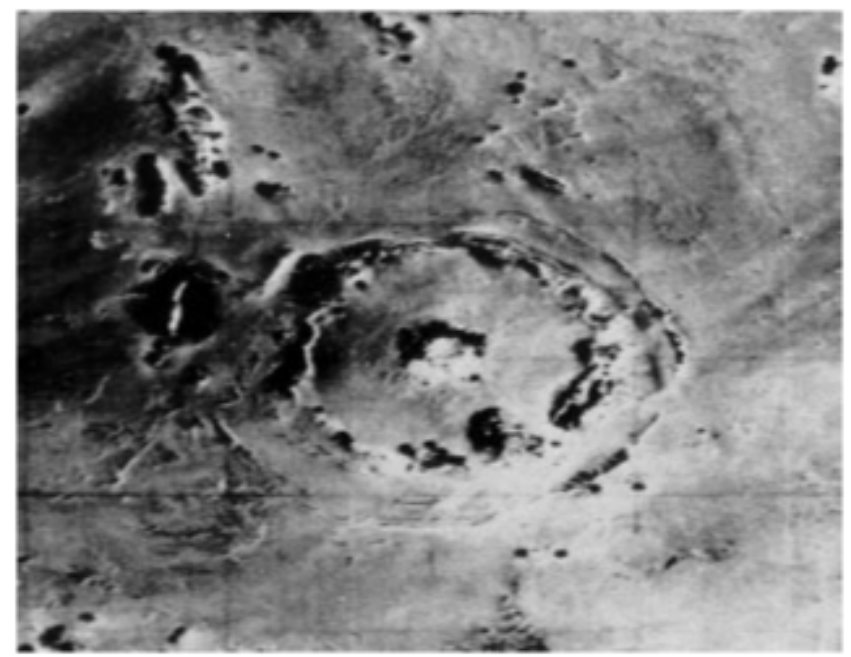

Figure5. The structure of the BP crater. (Taken from [15]).

\subsection{The Oasis Crater}

The structure of the Oasis crater shows a form of a single circular ring prominent with $5.1 \mathrm{~km}$ in diameter and a height of $100 \mathrm{~m}$. This crater lacks height in the middle. The effect of this impact extends to an external circle about $18 \mathrm{~km}$ in diameter (see figure6).

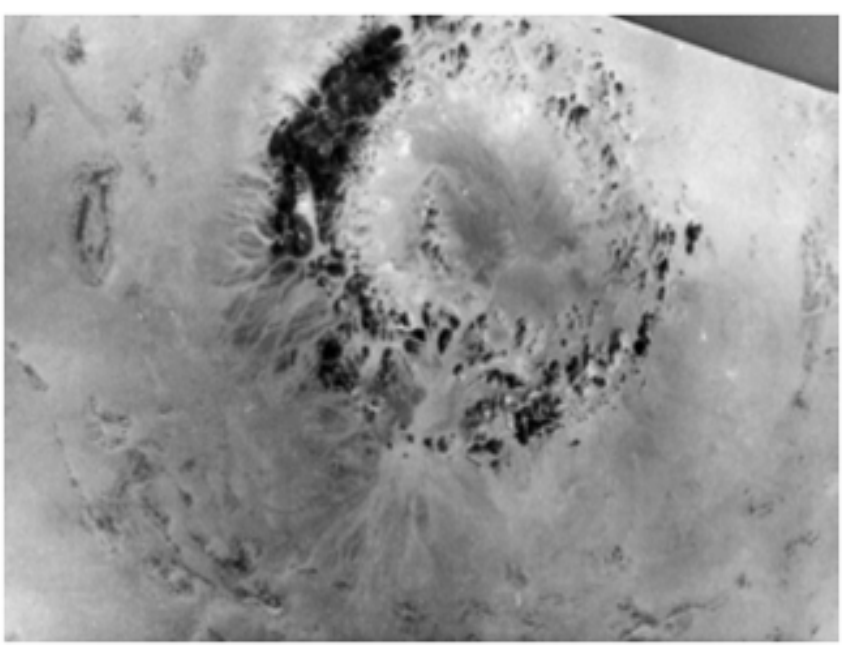

Figure 6. The structure of the Oasis crater. (Taken from [15]).

However, the inability of scientists to determine the age of both craters so far opened the door for new study despite the fact that a definitive conclusion about the relationship between the Libyan Desert Glass formation and the theory of meteorites impact with Earth has not been reached so far.

\subsection{Meteorites Impact Mechanism with Earth}

When meteorites collide with Earth, they pressed on the rocks, form a flow of shattered rocks (Melt Rock) and dust expelled into the atmosphere. These ejected materials, referred to as ballistics is called (Ejecta Blanket) [16]. This impact with Earth sends a shock wave to the rocks beneath which leads to crushed rocks into small pieces to form fragments. Some of these projectiles are hot enough (evaporate) and generate enough heat to melt some of these affected rocks (Breccia). Figure7 Shows the mechanics of a meteorite impact with Earth.
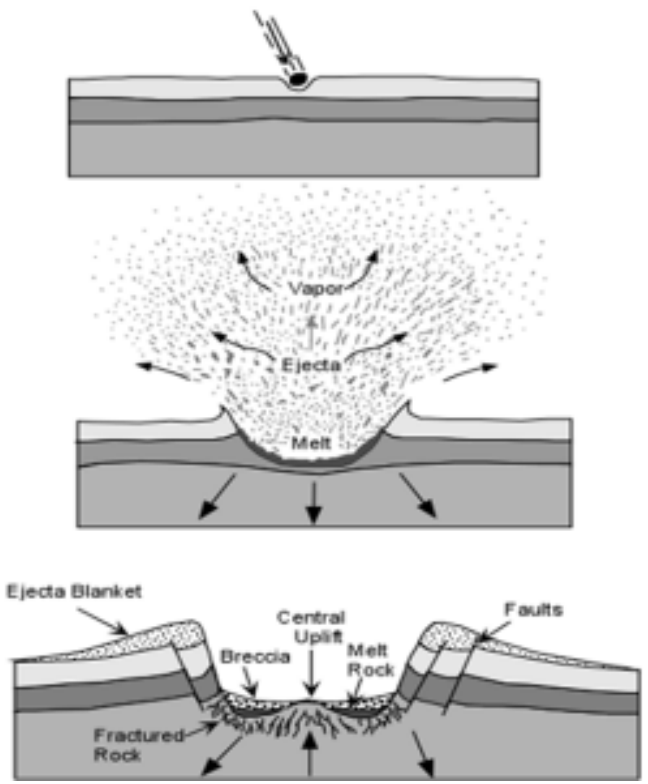

Figure 7. Shows mechanics of meteorites impact with land (Taken from [16]).

This shock wave enters the Earth and moves first as a compression wave. After a wave compressibility, the wave expands as a rarefaction wave and returns back to the surface. This causes a rise in the floor of the crater (central peak) as well as the crater edge outside. The cracking of rocks can also happen to rocks near the crater pit, becomes large and have a central set of loops [16].

The shape of the meteorite craters depends on several effects. Some of these effects are the nature of the rocks, the area of meteorites impact, size and speed of meteorites. Impacts of large meteorites with land may lead to the generation of craters with diameters large enough as to exceed many times meteorites diameters. These meteorite impacts with land generate explosive energy equivalent to explosion energy from one nuclear bomb to thousands of nuclear bombs. Therefore, impacts by meteorites represent one mechanism that could cause global catastrophes and seriously pose a natural hazard to life on Earth. Therefore, the subject of meteorite impact mechanism with the ground is an important topic in the field of scientific research. It has a global concern and is given the distinctive value of the leading universities in research possibilities related to this field. 
In this paper, a simple model for studying meteorites impact mechanism with ground presented in [17] was adapted. It has a reasonable approach and rests on fundamental quantity (energy). This model is applied for the first time to study the meteorite impact mechanism of BP and Oasis craters, in Libya.

\section{Relationship between Meteorite Kinetic Energy (KE) and Radius of the Crater ( $R$ )}

The most important factor in the formation of meteorite crater is the energy of meteorite impact. From the crater diameter formed (due to meteorite impact with Earth), the total energy of the meteorite and its mass before impact can be estimated.

Through the study of the mechanical meteorite impact with Earth, the first problem faced was that the mass of the meteorite and its speed are unknown. However, there are some assumptions that have been considered for the values of the meteorite energy and its size. Placing logical limits for meteorite speeds that the meteorite must travel at speed of not less than about $11 \mathrm{~km} / \mathrm{sec}$. This is equal to the lowest speed that can be given to a shell in order to overcome gravity and reach outer space. Logically it must have the same speed for anybody fallen from the sky, and must have a maximum speed of approximately $72 \mathrm{~km} / \mathrm{sec}$ [17]. Assuming that the density of iron meteorite type is $8000 \mathrm{~kg} / \mathrm{m}^{3}$ and Stone meteorite type is $4000 \mathrm{~kg} / \mathrm{m}^{3}$ and that the meteorite is perfectly spherical.

The first estimation is to assume that $100 \%$ the meteorite energy at impact goes to form meteorite crater and can be expressed in this description as follows:

$$
\text { Energy }_{\text {meteorite }}=\text { Energy } \text { excavation }
$$

Where Energy meteorite is the Potential energy is given as:

$$
\text { Energy }_{\text {meteorite }}=\mathrm{V} \times \mathrm{g} \times \rho_{\text {rock }} \times \mathrm{h}=\text { Energy }_{\text {excavation }}
$$

Where: $\mathrm{V}$ is the crater volume., $\mathrm{g}$ is gravity acceleration $\left(9.8 \mathrm{~m} / \mathrm{sec}^{2}\right)$., $\rho_{\text {rock }}$ is the density of rock and $\mathrm{h}$ is the crater depth.

Assuming that the shape of crater formed is spherical, the depth of the crater can be considered as equal to the crater radius R. Equation (2) can be rewritten as:

$$
\text { Energy meteorite }=2 / 3 \times \pi \times \mathrm{R}^{3} \times \mathrm{g} \times \rho_{\text {rock }} \times \mathrm{R}
$$

Or

$$
\text { Energy }_{\text {meteorite }}=2 / 3 \times \pi \times \mathrm{g} \times \rho_{\text {rock }} \times \mathrm{R}^{4}
$$

Of course, we can assume that not all of the impact energy of the meteorite goes in making meteorite crater but a large part of it is dissipated as heat and as a strong shock wave. Therefore, equation (2) can be rewritten in the general form as:

$$
\mathrm{E}_{\text {meteorite }}=\mathrm{E}_{\text {Shock }}+\mathrm{E}_{\text {Heat }}+\mathrm{E}_{\text {Excavation }}
$$

Taking into account the mechanism of the meteorite when entering the Earth's atmosphere and the explosion that it creates upon collision with the Earth surface, it is reasonable to assume that the meteorite's energy upon impacting with the Earth's surface $80 \%$ of it goes to heat and $15 \%$ goes to strong shock wave. The rest of the meteorite's energy goes in making the meteorite crater. In other words: $\mathrm{E}_{\text {Heat }}=80 \% \mathrm{E}_{\text {meteorite. }}, \mathrm{E}_{\text {Shock }}=15 \% \mathrm{E}_{\text {meteorite., and }} \mathrm{E}_{\text {Excavation }}=$
$5 \% \mathrm{E}_{\text {meteorite }}$

From equation (2), we have:

$2 / 3 \times \pi \times g \times \rho_{\text {rock }} \times \mathrm{R}^{4}=5 \times 10^{-2} \times \mathrm{E}_{\text {meteorite }}=5 \times 10^{-2} \times \mathrm{K} . \mathrm{E}_{\text {meteorite }}$

Where the kinetic energy of the meteorite can be calculated as a function of the density of the impact rocks and the radius of the crater $(\mathrm{R})$ and is given by:

$$
\mathrm{K} . \mathrm{E}_{\text {meteorite }}=4.10 \times 10^{6} \times \rho_{\text {rock }} \times \mathrm{R}^{4}
$$

The initial pressure upon impact can be calculated as a function of target density and the square of the meteorite's speed and is given by the equation:

$$
\mathrm{P}_{\text {initial }}=\rho_{\text {target }} \times \mathrm{v}^{2} \text { meteorite }
$$

The volume of the displaced rocks upon impact can be calculated taking into account that the volume of the crater is a half sphere and is given by equation:

$$
\mathrm{V}_{\text {rock }}=\left(\mathrm{V}_{\text {crater }}-\mathrm{V}_{\text {meteorite }}\right) / 2
$$

The thickness of the melted rocks can also be calculated, assuming it equals to $6 \%$ of the crater diameter (D), and is given as:

$$
\text { Melted rock } \text { thickness }=0.06 \times \mathrm{D}_{\text {crater }}
$$

The volume of the melted rock is given as a function of the diameter of the crater and thickness of the melted rock and is given as:

$$
\mathrm{V}_{\text {melt }}=\mathrm{V}_{\text {crater }}(\mathrm{D})-\mathrm{V}_{\text {crater }}[\mathrm{D}-(2 \times 0.06 \mathrm{D})]
$$

\section{Results and Discussion}

Now we can calculate the total energies of the meteorites that created the BP and Oases craters which have diameters $2 \mathrm{Km}$ and $18 \mathrm{Km}$ respectively. These craters are located in the Kufra Basin near the Libyan-Egyptian border as shown in figure1. Starting with equation (4), and assuming that

$\mathrm{E}_{\text {Excavation }}=5 \% \quad \mathrm{E}_{\text {meteorite }}$

Table1. Shows the results of calculation for the total energies of meteorites that created the BP and Oases craters. Knowing that: 1 Mton $(\mathrm{TNT})=4.1843 \times 10^{15}$ Joule. 
Table1. Total energies of the meteorites (kinetic energy, K.E.) and their equivalent to (TNT).

\begin{tabular}{llll}
\hline Crater & $\mathbf{E}_{\text {Excavation }}(\mathbf{J})$ & K.E $(\mathbf{J})$ & $\begin{array}{l}\text { K.E }= \\
\text { Mton(TNT) }\end{array}$ \\
\hline B.P & $2.2976 \times 10^{16}$ & $4.5953 \times 10^{17}$ & 109.8299 \\
Oases & $1.5072 \times 10^{20}$ & $3.0149 \times 10^{21}$ & $7 \times 205710^{9}$ \\
\hline
\end{tabular}

Knowing the kinetic energy of the meteorites from table1. and assuming that the velocity of the meteorites is equal to $11 \mathrm{Km} / \mathrm{s}$, which is corresponding to the lowest energy that can be given to a shell in order to overcome gravity and reaches outer space, the mass of meteorites can be estimated from the relationship: K.E $=0.5 \times \mathrm{m} \times \mathrm{v}^{2}$ From which the masses of BP and Oases meteorites are determined:

$$
\begin{gathered}
\mathrm{m}_{\mathrm{BP}}=7.595 \times 10^{9} \mathrm{~kg} \\
\mathrm{~m}_{\text {Oases }}=6.157 \times 10^{11} \mathrm{~kg}
\end{gathered}
$$

The initial pressure in both craters is calculated using equation (8).

$$
\mathrm{P}_{\text {initial }}=1120 \times(11000)^{2}=1.355 \times 10^{11} \mathrm{~Pa}
$$

Assuming the velocity of meteorite is $11 \mathrm{~km} / \mathrm{s}$ and the density of the impact target is $1120 \mathrm{~kg} / \mathrm{m}^{3}$ which is equivalent to the density of sand and representing the environment surrounding the impact area.

The volumes of BP and Oases meteorites can be calculated using the determined values of BP and Oases meteorites masses and assuming that the meteorites are spheres and have densities approximately equal to $4000 \mathrm{~kg} / \mathrm{m}^{3}$ (stony meteorites). These volumes are given as:

$$
\begin{gathered}
\mathrm{V}_{\mathrm{BP}}=1.898 \times 10^{6} \mathrm{~m}^{3} \\
\mathrm{~V}_{\text {Oases }}=1.537 \times 10^{8} \mathrm{~m}^{3}
\end{gathered}
$$

From which the radii of both meteorites are given as:

$$
\begin{aligned}
\mathrm{R}_{\mathrm{BP}} & =76.38 \mathrm{~m} \\
\mathrm{R}_{\text {Oases }} & =332.39 \mathrm{~m}
\end{aligned}
$$

\begin{tabular}{|c|c|c|c|}
\hline Crater & $\begin{array}{l}\text { Volume of } \\
\operatorname{Rock}\left(\mathrm{m}^{3}\right)\end{array}$ & $\begin{array}{c}\text { Melt } \\
\text { thickness(m) }\end{array}$ & $\begin{array}{c}\text { Melt } \\
\text { Volume }\left(\mathrm{m}^{3}\right)\end{array}$ \\
\hline $\mathrm{BP}$ & $2.0923 \times 10^{9}$ & 120 & $6.6678 \times 10^{8}$ \\
\hline Oasis & $1.5259 \times 10^{12}$ & 1080 & $4.8608 \times 10^{11}$ \\
\hline
\end{tabular}

Table2. shows the calculated values for the volumes of displaced rock, thickness of melted rocks, and volumes of melted rocks, using equation (9), (10), (11), and other relevant calculations in the text.

Table2. Shows the estimated values for the impact mechanisms due to BP and Oases meteorites.

Now the calculations will focus on the Oases crater because its much larger than the BP crater. The BP crater maybe created due to huge meteorite bounce from the Oasis crater, or maybe due to other meteorite impact, and other possibility that due to a huge meteorite that had been split in the air before impact.

Since the volume of the melted rock of Oasis is determined (see table2), its mass can be estimated. Knowing the density of the target materials $\left(1120 \mathrm{~kg} / \mathrm{m}^{3}\right.$,sand), the mass of the melted rock of the Oasis crater is calculated and given as: $\mathrm{M}=5.4441 \times 10^{14} \mathrm{Kg}$

Since the total energy of the Oasis meteorite (see table1) is made up of three parts (see equation(5)), the assumptions made in this paper (see text) are applied and the fraction of energy converted to heat ( $80 \%$ of total meteorite energy) is estimated as follows:

$$
\mathrm{E}_{\text {heat }}=0.8 \times 3.0149 \times 10^{21}=2.4119 \times 10^{21} \mathrm{~J}
$$

The change of temperature on the ground due to heat generated upon impact can be calculated using heat capacity relationship and is given as:

$$
\mathrm{Q}=\mathrm{M} \times \mathrm{c} \times \Delta \mathrm{T}
$$

Where $\mathrm{M}$ is the mass of melted rock (Oasis crater), $\mathrm{c}$ is the specific heat capacity ( $\left.380 \mathrm{~J} /\left(\mathrm{kg} . \mathrm{C}^{0}\right)\right)$, and $\Delta \mathrm{T}$ is the change in temperature. It follows that:

$$
\Delta \mathrm{T}=5337.8 \mathrm{C}^{0}
$$

This striking result describing the change in temperature for the target materials, as a result of Oasis meteorite impact, could explain the way Libyan Desert Glass was formed. Since the melting point of sand (silicon dioxide, or Quartz) is about $1723^{\circ} \mathrm{C}$, heating sand to a temperature $\left(5337.8^{\circ} \mathrm{C}\right)$, much larger than its melting point will transform melting sand to a vapor.

When the Oasis meteorite hit the ground, a great amount of sand was vaporized by the extreme energy of the impact. This led to the formation of a large cloud in the air. This huge cloud traveled some distance from the impact area by means of wind movement. This large cloud then cooled down and condensed. Condensation of this vapor produced droplets of melted glass. This explains the presence of the Libyan Desert Glass in an area of approximately $6500 \mathrm{~km}^{2}$ between the dunes in the southwest corner of the Great Sand Sea in the west of Egypt, near the Libyan border (see figure1).

\section{Conclusion}

The discovery of Libyan Desert Glass in the west of Egypt, near the Libyan border, its source of formation has become the subject of controversy from some of the perspective researchers, that still has not been resolved. In this paper, description of Libyan Desert Glass formation was introduced. Theories explaining its formation were presented. New interpretation for Libyan Desert Glass is presented. This interpretation is based on meteorite impact mechanism. Calculations have shown that change in temperature for the target materials (sand) as a result of 
meteorite impact could explain the way Libyan Desert Glass was formed. These results found conclude that an impact origin of Libyan Desert Glass is consistent with the structure description of Oasis crater. Further work in this fascinating topic should help to provide additional relevant data.

\section{Acknowledgement}

We would like to express our gratitude to the Head of The Faculty of Science, University of Benghazi for kind support and encouragement about this work. We thank also all Faculty Members of Physics Department.

\section{References}

[1] Christian Koeberl., Proceeding of the " Silica '96 “ Meeting, 1997, pp 121- 158

[2] Barnes V. E. and Underwood J. R. JR., “ New Investigations of the strewn field of Libyan Desert Glass and its Petrography"., Earth Planetary Science Letters, 30, 1976, pp $117-122$

[3] Bagnold R. A., " A further journey through the Libyan Desert"., The Geographical Journal (London), 82, 2, 1933, 103-129

[4] Bagnold R. A., Myers O. H., Peel R. F. and Winkler H. A., "An expedition to the Gilf Kebir and Uweinat". The Geographical Journal (London), 93, 4, 1939, pp 281-313

[5] Clayton P.A. and Spencer L.J., " Silica glass from the Libyan Desert”., Min. Mag., 23, 1934, pp 501-508.

[6] Weeks, Underwood, and Giegengack, 'Libyan Desert Glass: A Review', J. Noncrystalline Solid, v.67, 593 (1984).
[7] Seebaugh and Strauss, 'Libyan Desert Glass: Remnants of an Impact Melt Sheet', Lunar and Planetary Science $15^{\text {th }}$ Conference, 1377 (1984).

[8] Begosew Abate et. al., "BP and Oasis impact structures, LIBYA: Preliminary Petrographic and Geochemical Studies, and Relation to Libyan Desert Glass"., Lunar and Planetary Science XXVIII, 1997, Abstract: 1620.pdf

[9] Storzer D and G.A. Wagner, Meteoritics 12, 1977, pp 368

[10] http://www.b14643.de/Sahara/LDG/

[11] The Libyan Desert Geography., Libyan Desert Glass, http://www.fjexpeditions.com

[12] https://www.google.com.ly/\#q=LIBYAN+DESERT+ GLASS

[13] http://www.bibliotecapleyades.net/ancientatomicwar/esp_an cient_atomic_04d.htm

[14] John W. Olsen and James R. Underwood http:/www.saudiaramcoworld.com/issue/197905/desert.glas s-an.enigma.htm

[15] Christian Koeberl., Wolf Uwe Reimold., and Jeff Plescia., "BP and Oasis Impact Structures, Libya: Remote Sensing and Field Studies", Impact Tectonics, 6, Springer, 2005, pp. 161-190

[16] Stephen A. Nelson, Meteorites, Impacts, \& Mass Extinction, http://www.tulane.edu/ sanelson/Natural_Disasters/impacts. $\mathrm{htm}$

[17] Ben A. van der Pluijm., "How to Build a Habitable Planet"., Geological Sciences, 1998. www.umich.edu/ gs265/meteor.htm 